\title{
The behavioral intention to adopt XBRL in the accounting firms: Tunisian context
}

\author{
Helmi Hentati ${ }^{1, a}$, Manel Borchani Maktouf ${ }^{\mathrm{b}}$ and Neila Boulila \\ Taktak $^{\mathrm{a}}$ \\ a IHEC Carthage, University of Carthage, Tunisia \\ ${ }^{\mathrm{b}}$ IHEC Sfax, University of Sfax, Tunisia
}

\begin{abstract}
Research Question: What are the factors that influence the intention of Tunisian accounting firms to adopt the "XBRL" accounting information system?

Motivation: The low level of awareness about XBRL adoption especially in developing countries and the latest developments of this information system in favor of Artificial Intelligence which should be considered as a motivational tool for adoption.

Idea: the choice to adopt an innovation depends on several factors. This study uses the technology acceptance model theory to examine intentions in order to explore the factors influencing adoption of XBRL technology.
\end{abstract}

Data: The survey data was collected by means of a self-administered questionnaire sent to accounting firms.

Tools: Logistic regression, which allowed us to test the influence of each factor in three categories: technical, organizational and environmental on the behavioral intention to adopt XBRL.

Findings: Perceived benefits and a qualified staff among the main motivating factors for XBRL adoption as well as mimetic and normative pressure can be a source of reinforcing adoption intentions. However, the communication factor is suggested as an unexpected demotivating factor for XBRL adoption.

Contribution: we have two contributions: the first one managerial for regulatory authorities or business owners in order to encourage the intentions of the adoption of this accounting information system and other similar technologies. The second contribution to the previous literature since we have used new data collected from Tunisian companies and present new results in a developing country context.

1 Corresponding author: Helmi Hentati, PhD student, IHEC Carthage, University of Carthage, Tel (+216) 53099292, email addresses: helmihentati@yahoo.f 
Keywords: XBRL, Behavioral intention, TOE, Tunisian context

\section{JEL codes: M49}

\section{Introduction}

The increasing progression of digitalization in all fields has become a primordial need today, that can influence our practice and habit. This leads to the birth of new concepts, such as the new XBRL reporting approach. This new technology is necessary and plays an important role in organizing, producing and communicating financial information. Given the current reporting environment and the increasing attention paid to financial reporting in the wake of financial scandals, it is time to explore the potential of the increased transparency of financial information offered by XBRL technology and to examine the theoretical ground for better adoption in this context (Rawashdeh \& Rawashdeh, 2021).

This phenomenon of digitizing reports appeared with its first generation, the majority of which were PDF and HTML versions. A few years later, a second generation of digital reports was born, to ensure a certain degree of efficiency and transparency in the production process and financial information, by standardizing financial reports using a digital reporting framework that would allow for more analysis and more interaction among information (Hoitash et al., 2021). This standard is known as XBRL. According to Elansary et al. (2020), it is necessary to clarify the strategy for authorities and managers in order to disseminate XBRL in organizations and benefit from this revolutionary financial information management technology.

Today, this standard is known as XBRL, which is widely accepted by the international accounting community and adopted in several countries (XBRL International, 2019). Recent studies (Ilias et al., 2020) have indicated that many countries have adopted XBRL, such as: New Zealand (Cordery, et al., 2011), United Kingdom (Mousa, 2009), South Africa (Nel \& Steenkamp, 2008), Jordan (Abed, 2018), Germany (Felden, 2011), Australia (Indrit \& Rao, 2007), Italy (Rosa \& Caserio, 2013), Malaysia (Ilias et al., 2017), Indonesia (Wulandari \& Ali, 2019), Morocco (Elansary et al., 2020), for which we suggest that it is very interesting to know how it works in Tunisia.

Tunisia is undergoing major transformations following the phenomenon of digitalization, which requires a change in order to follow the trends to ensure certain competitiveness and the requirement of the various actors, including foreign investors. That is why, it is essential that the adaptation of new technology whether at the macro or micro economic level can have or ensure a lever of development and follow the path of this digital transformation. Especially there are guidelines 
and strategies led by the Tunisian State, for example: the national strategic plan "Digital Tunisia 2020" digital transformation for public services "GOTECH" and " Smart Tunisia" under the direction of the Ministry of Communication Technologies and Digital Economy of Tunisia.

The Order of Chartered Accountants of Tunisia (OECT) takes a proactive dimension to digitalization phenomenon by indicating its role during this 33rd congress in February 2020, under the theme "The digital revolution: challenges and contribution to the Tunisian economy", it will be tempted to demystify certain concepts (Big Data, XBRL, RPA, Machine learning, deep Learning, Biotechnology, Fin-Tech and Block Chain) in order to use the digital component in accounting firms.

While the first professional discussion on the subject adoption of XBRL, which was addressed by chartered accountants in 2006 to become aware of this XBRL and prepare the main steps to adopt it. Ten years later, a professional association was created Smart Business Reporting Tunisia. This association aims to promote XBRL as a free standard for the exchange and processing of financial and economic information for companies. However, efforts to promote this technology have so far failed. Indeed, we conducted a preliminary survey on XBRL in firms, before starting our study we noticed that $82 \%$ of respondents are not familiar with XBRL so it is necessary to investigate the role of technical, organizational and environmental factors on the intention to adopt XBRL, in accounting firms in Tunisia.

The document proceeds as follows. The second section provides literature review and research questions. The third section shows the methodology. In The fourth section, we present the discussion of the results and in the fifth section, we propose an additional test and finally a conclusion will be presented.

\section{Literature review}

\subsection{Theoretical background}

In attempting to study the diffusion of any new technology, it is inevitable that the Technology Acceptance Model (TAM) theory is the first step. This theory of information systems was originally proposed by Davis (1989). Derived from psychologically based Theories of Reasonable Action (TRA) and the Theory of Planned Behavior (TPB), our study the TAM model is more effective than the Diffusion of Innovation Theory (DOI) in measuring the potential adoption of XBRL since TAM can use intentions as an explanatory variable in contrast to DOI theory (Rogers, 1995). TAM theory focuses on the individual's intention towards the acceptance of an innovation which depends on their perceived usefulness and ease of use (Lai, 2017). 
This research is also based on the Institutional theory which focuses on the environmental factors of the organization, such as cognitive, normative and regulatory elements. This theory emphasizes the role of environmental forces that drive organizations to adopt innovations. In this sense, this theory is useful to study the factors that can influence the adoption of XBRL through these three types of pressure (DiMaggio \& Powell, 1983) coercive, normative and mimetic as explanatory factors in the phenomenon of adoption by accounting firms.

Tornatzky et al. (1990) had provided a comprehensive framework for understanding technology adoption which was composed of three contexts: technological, organizational and environmental. This model has been used in most of the research work. It is dealing with factors that can influence the adoption of XBRL (Doolin \& Troshani, 2007; Mandilas et al., 2009; Mousa, 2011; Steenkamp \& Nel, 2012; Henderson et al., 2012), Big Data adoption (Manohar, 2020), Block Chain adoption (Hanna et al., 2020) and adoption of artificial Intelligence (Stenberg et al., 2020).

\subsection{Adoption studies}

Since the introduction of XBRL, most researchers have discussed the concept of XBRL and the factors that can influence the adoption of this technology. According to Bartolacci et al. (2020) 31 article on XBRL has been published for 20 years among these studies: the study by ELansary et al. (2020) looked at the determinants of XBRL adoption in Morocco and their conclusion showed that perceived usefulness, ease of use, normative pressure, managerial attitude and organizational expertise were the most important factors influencing XBRL adoption in Morocco. Moreover, Ayoub et al. (2020), concluded that the human factor is important for the success of the adoption of XBRL for small and medium enterprises in Lebanon. Alkhatib et al. (2019) examined the factors influencing the voluntary adoption of XBRL in the UK. Their results indicate that the relative advantage of management support and company technological competence had a significant effect on the voluntary adoption of digital technologies. Furthermore, Muchlis et al. (2019) analyzed the factors influencing the implementation of XBRL in Indonesia. They found that the size and profitability of a company are the financial characteristics of the company, which determine the early adoption of XBRL. In addition, Lakovic et al. (2019) investigated the determinants of XBRL adoption. Their results of Environmental factors have the greatest influence, followed by technical factors and finally organizational factors.

Felden et al. (2011), who examined the factors influencing the adoption of XBRL in Germany using institutional theory and TAM, found on the one hand that the influence of social groups is the most important factor and on the other hand the perceived advantages. In the same context, Pinsker and Felden (2016) showed that 
there is a positive relationship between professional role and normative pressure and the intention to adopt XBRL. Indeed, Henderson et al. (2012) used a theoretical model based on the TOE framework, show that relative advantage, compatibility and complexity strongly influenced the decision to adopt XBRL.

Nevertheless, other studies have shown that relative advantage and stakeholder involvement are important factors that can motivate adoption (Mousa, 2011; Azam \& Taylor, 2011). Doolin and Troshani (2007) have made the important point that regulators can also force the implementation of XBRL for their reporting needs, while highlighting the important role of staff. However, factors that impede adoption include: complexity of the technology (Doolin \& Troshani, 2007; Moussa, 2011), low operating awareness (Troshani \& Rao, 2007), lack of technical knowledge (Steenkamp \& Nel, 2012) and implementation costs (Cordery et al., 2011).

\subsection{Research conceptualization}

\subsubsection{Technical factors}

Technical factors have a major influence on the adoption of innovations (Abed, 2020). This research considers three important elements for this category of factors:

Infrastructure: is the set of components that form the basis of operation of a technology, they include hardware and other elements (Laan, 2011). An adequate infrastructure is a basis for the adoption of new innovations (Chiu \& Yang, 2018). The existence of the technical infrastructure in a Firm is an important variable in the adoption of new technologies (Schultz \& Slevin, 1975). In other words, it should be noted that a firm needs to have a fairly developed infrastructure that can facilitate the implementation of XBRL. This has been asserted by authors (Awa et al., 2017; Albar et al., 2017) who insisted that this variable is an important vector for the diffusion of a technology. The study by Awa et al. (2016) focused on factors that can influence adoption. They found that the infrastructure has a curative role in ERP adoption. In addition, the infrastructure variable has been tested in other studies, such as E-business (Choshin \& Ghaffari, 2017), Egovernment (Al-rawahna et al., 2018).

Perceived advantages: Tornatzky and Klein (1982) found that the relative advantage of an innovation, its compatibility with organizational needs, existing systems and its complexity were consistently associated with the adoption of innovative behaviors. The published research on XBRL has focused on the expected benefits of using it and the technical mechanisms by which it works. Doolin and Troshani (2004), in order to identify the usefulness and simplicity of 
the technology, considered that the technological aspect of an innovation can affect the acceptance of a technology (Davis, 1989). This depends on the existence of XBRL benefits that can have a positive impact on the organization's adoption of this information technology. It also depends on the existence of XBRL benefits that can have a positive influence on the organization's adoption of this information technology. In addition, the study by Pinsker and Li (2008) has suggested that the ease of use affects user's attitudes towards the adoption or acceptance of XBRL. Also, a meta-analysis study on XBRL conducted by Elansary et al. (2020) showed that relative benefit plays an important role in the decision to adopt XBRL. Therefore, the greater the advantage is perceived, the more likely organizations will adopt XBRL (Mousa, 2011; Azam \& Taylor, 2011; Cordery et al., 2011; Henderson et al., 2012).

Expertise: is defined in this study as the level of specialized knowledge and skills in XBRL to provide reliable support for the decision to implement XBRL (Ayoub et al., 2020). One of the most important variables in the adoption of technology is the skill set of computer work-staff (Giotopoulos et al., 2017). Henderson et al. (2012) found that organizations with good Internet skills are more likely to adopt XBRL. Other studies by Siew et al. (2020) emphasized the critical role of internal resources including human capital. Thus, the element of information system and networking expertise is introduced as a factor since it is essential for XBRL users to have sufficient knowledge to ensure that the information required by employees feels secure with the new changes brought about by the technology (Batcha et al., 2017) and therefore promotes the adoption of XBRL. The research for Antônio et al. (2016) showed that there is a positive relationship between the knowledge required from staff and the adoption of XBRL. Therefore, the first research question developed is:

RQ1. Can technical factors influence the intent of XBRL adoption in the Tunisian context?

\subsubsection{Organizational factors}

Communication: This variable is considered very important for such a technology adoption decision. Communication is used to ensure the existence of the technology and the procedures for its implementation (Dmour et al., 2017). It can also encourage adoption by developing mechanisms that progressively lower knowledge barriers (Siangu, 2015). As a result, firms can help others to accumulate more knowledge (Mannan et al., 2017). Previous researches on other innovations such as database technologies and software development practices have highlighted the importance of adopting information channels (Nilakanta \& Scamell, 1990). In addition, a study by Mbaru, (2018) has showed that the organization is more likely to adopt the technology and this depends on the degree of communication and media coverage of the innovation. 
Size: it is considered as a variable to identify organizational characteristics that reflect the capacity of the organization when adopting a new technology (Mathauer \& Hofmann, 2019). Nguyen and Petersen, (2017) proposed that the firm size is strongly related to the financial capacity of organizations to bear the costs of implementing a new innovation. The inability to allocate the necessary resources, including the financial capacity of the organization, (Siew et al., 2020; Lowe et al., 2018 ) is also a significant barrier to innovation adoption. This was proved by previous studies showing that the company size is one of the main factors in the decision to adopt XBRL (Muchlis et al., 2019; Abdolmohammadi et al., 2019). Callaghan and Nehmer (2009) have examined a sample of U.S.A organizations that voluntarily adopt XBRL and also found that the size variable is positively and significantly associated with voluntary XBRL adoption. As a result, the second research question was developed:

RQ2. Can Organizational factors influence the intent of XBRL adoption in the Tunisian context?

\subsubsection{Environmental factors}

The last category of environmental factors is principally based on institutional theory. Therefore, we will have three variables:

Mimetic pressure: Arising from competitive pressure and can lead to the same adoption decisions through imitative behavior from one firm to another similar firm (DiMaggio \& Powell, 1983). According to Oliveira et al. (2019) mimetic pressures reflect the act of imitating other structurally similar organizations. In order to avoid uncertainty, companies rely on the experience of their competitors. This isomorphism is manifested by a significant number of organizations in the same sector adopting an innovation, while others will also do so to avoid the risk of being perceived as less innovative (Awa et al., 2017). The adoption of XBRL is seen as a competitive advantage to position the organization as a "leader" and thus attracts customers (Pinsker \& Li, 2008; Piechocki et al., 2009). These arguments suggest that a firm may adopt XBRL because other firms in the same industry have also adopted it in order to remain competitive. However, previous researches have shown that the influence of mimetic pressure on the adoption of other similar technologies such as, E-government (Dias, 2020) and ERP adoption (AlBar et al., 2019).

Coercive pressure: Resulting from both informal and formal pressure exerted on the organization by another one, which it depends (Powell \& DiMaggio, 1991). These pressures may come from government regulators, dominant suppliers or customers,... Generally, from parties that have control and authority over the target business (Lutfi, 2020). Previous researches have shown that the influence of coercive pressures on technology adoption has found a high significance for coercive pressures on XBRL adoption (Cordery et al., 2011), as well as on XBRLlike technologies (Oliveira et al., 2019; Amade et al., 2020). Another interesting 
study by Lowe and Locke (2006) on XBRL adoption has analyzed the implementation of complex technologies. Its results have revealed the role of coercive pressure, in particular, that pressure from regulators which is essential in the early stages of technology adoption.

Normative pressure: Arising from shared norms and values among members of a network it can be enforced through professional organizations (DiMaggio \& Powell, 1983). This type of pressure reflects the way in which companies are expected to conform to professionalism by adopting organizational behavior that can lead to the adoption of technologies (Lutfi, 2020). In addition, the few empirical works conducted that normative pressure can have a positive influence on the adoption of innovations between organizations in systems such as XBRL (Elansary et al., 2020) and SaaS (Martins et al., 2019). Consequently, the third research question was proposed:

RQ3. Can Environmental factors influence the intent of XBRL adoption in the Tunisian context?

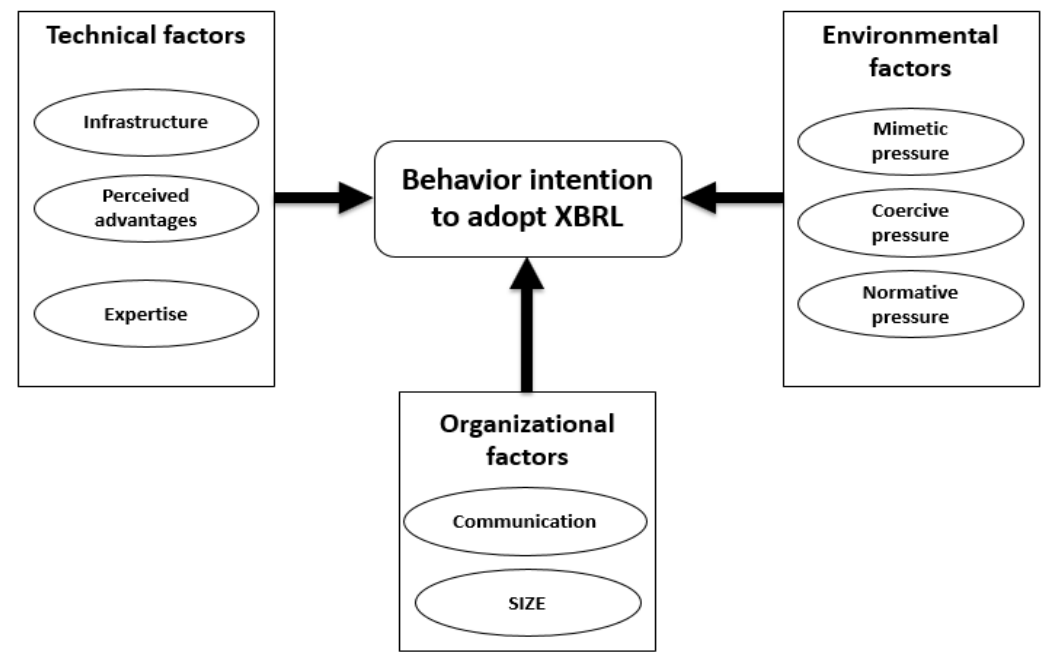

Figure 1. Initial Conceptual Research Framework

\section{Methodology}

\subsection{Data collection}

Data collection is based on a self-administered questionnaire addressed to accountants. This questionnaire was pre-tested before being distributed to ensure that the questions were well formulated and understandable. We used the snowball technique for the selection of the respondents. We sent 320 questionnaires to the accounting firms in Tunisia. We collected 174 answers. We have deleted two 
answers which contain missing data. Therefore, we eliminated these questionnaires in order to have 172 duly completed questionnaires giving a response rate of 53.75

$\%$ in a period of 90 days (from February 15 to May 15 2020).

After data collection, the reliability of the internal consistency of a questionnaire was verified. The researchers stipulate that a value of this coefficient greater than 0.5 is considered acceptable. The Cronbach alpha value $(\alpha)$ is 0.615 for all items in the questionnaire indicating that the responses generated for all items used in this study are sufficient.

\subsection{The empirical model}

In our study, we used the binary logistic regression model as follows:

BI_XBRLi $=\beta 0 \mathrm{i}+\beta 1 \mathrm{INFRAi}+\beta 2 \mathrm{ADPEi}+\beta 3 \mathrm{EXPi}+\beta 4 \mathrm{COMi}+\beta 5$
$\mathrm{SIZEi}+\beta 6 \mathrm{MIMi}+\beta 7 \mathrm{COERi}+\beta 8 \mathrm{NORi}+\varepsilon \mathrm{i}$

$\beta=$ constant; i: respondent ; $\boldsymbol{\varepsilon}$ : error

BI_XBRL: $=1$ if the respondent intends to adopt XBRL, 0 otherwise.

INFRA $=$ the total value of infrastructure items divided by the total number of infrastructure items.

ADPE $=$ the total value perceived advantage items divided by total number of perceived advantage items.

EXP: $=$ the total value of the items in the expertise divided by the total number of items in the expertise.

$\mathrm{COM}=$ the total value of the items in the communication divided by the total number of items in the communication.

SIZE $=$ the total value of size items divided by the total number of size items.

$\mathrm{MIM}=$ the total value of the mimetic items divided by the total number of mimetic items.

COER $=$ the total value of the items in the coercive divided by the total number of items in the coercive.

NOR $=$ the total value of normative pressure items divided by the total number of normative items.

\section{Statistical results}

\subsection{Descriptive statistics}

Table 1 summarizes the demographic information of the respondents. Our sample is considered quite young. In terms of gender, there are fewer women than men in our survey. In terms of the distribution of our sample, most of our sample members are auditors and chartered accountants. 
Table1. Demographic Information of the Survey Respondents

\begin{tabular}{|c|c|c|c|c|c|c|c|c|}
\hline Gender & Freq & $\%$ & Position Title & Freq & $\%$ & Age & Freq & $\%$ \\
\hline Male & 96 & 55.8 & Auditors & 82 & 47.7 & Under 35 & 78 & 45.9 \\
\hline Female & 76 & 44.2 & $\begin{array}{c}\text { Chartered } \\
\text { accountants }\end{array}$ & 67 & 39.0 & [ $35 ; 45]$ & 79 & 45.4 \\
\hline- & - & - & Tax partners & 23 & 13.3 & Over 45 & 15 & 8.7 \\
\hline Total & 172 & $100 \%$ & Total & 172 & $100 \%$ & Total & 172 & $100 \%$ \\
\hline
\end{tabular}

Table 2 shows that the variable Perceived advantages "ADPE" has the highest mean (3.7810) in the category of technical factors, for the category of organizational factors communication "COM" has a mean higher than the mean of all the variables (4.2035) and for the size has the lowest standard deviation $(0.65333)$ in our research. For the category of environmental factors, we noticed the variable mimetic pressure "MIM" with a standard deviation equal to a (1.22060) and the coercive variable "COER" has a higher mean (4.0407) in this category.

Table 2. Descriptive statistics of variables

\begin{tabular}{cccccc}
\hline Variables & $\mathbf{N}$ & Minimum & Maximum & Mean & $\begin{array}{c}\text { Standard } \\
\text { Deviation }\end{array}$ \\
\hline INFRA & 172 & 2.00 & 5.00 & 3.7442 & 0.85752 \\
ADPE & 172 & 1.33 & 5.00 & 3.7810 & 0.88697 \\
EXP & 172 & 1.00 & 5.00 & 3.2384 & 0.99920 \\
COM & 172 & 2.00 & 5.00 & 4.2035 & 0.86308 \\
SIZE & 172 & 2.00 & 5.00 & 3.7965 & 0.65333 \\
MIM & 172 & 0.00 & 4.00 & 1.1744 & 1.22060 \\
COER & 172 & 2.00 & 5.00 & 4.0407 & 0.84020 \\
NOR & 172 & 2.00 & 5.00 & 3.2267 & 0.90210 \\
\hline
\end{tabular}

According to Table 3, the majority of respondents (60\% of the sample) intend to adopt XBRL. This explains why the perception of XBRL is positive and why this technology can be applied in the future. As anticipated for the age, we noticed that the age group under 35 years is the most categories that agree with the adoption of the XBRL technology with 58 respondents. This is explained by the positive link between the adoption of XBRL technology and the youth of the population (Boulianne \&Theocharis, 2020). However, the class of auditors are the most agree with the intention of the implementation because it makes the information transparent and easy to analyze. This was confirmed by Rosa and Caserio (2013) in the Italian context. On the other hand, the accountants present a majority that did not agree with the intention of the adoption of XBRL, this reflects the concern about the cost of implementation. 
Table 3. Interaction between dependent variable and demographic information

\begin{tabular}{|c|c|c|c|c|}
\hline \multicolumn{5}{|c|}{ AGE } \\
\hline BI_XBRL & Under 35 & {$[35 ; 45]$} & Over 45 & Total \\
\hline 0 & 20 & 38 & 11 & 69 \\
\hline 1 & 58 & 40 & 4 & 103 \\
\hline \multicolumn{5}{|c|}{$\begin{array}{c}\text { Position Title } \\
\end{array}$} \\
\hline BI_XBRL & Auditors & $\begin{array}{c}\text { Chartered } \\
\text { accountants }\end{array}$ & Tax partners & Total \\
\hline 0 & 24 & 34 & 11 & 69 \\
\hline 1 & 58 & 33 & 12 & 103 \\
\hline
\end{tabular}

Note: BI_XBRL is equal to 1 if the respondent intends to adopt XBRL, otherwise equal 0.

\subsection{Correlation matrix}

The values shown in Table 4 are less than 0.7 . So we do not have a multicollinearity problem.

Table 4. Pearson Correlation Matrix:

\begin{tabular}{|c|c|c|c|c|c|c|c|c|c|}
\hline $\begin{array}{c}\text { Les } \\
\text { variables }\end{array}$ & BI_XBRL & INFRA & ADPE & EXP & COM & SIZE & MIM & COER & NOR \\
\hline BI_XBRL & 1 & $0.289^{* *}$ & $0.343^{* *}$ & $0.416^{* *}$ & -0.123 & $0.327^{* *}$ & 0.020 & -0.074 & $0.226^{* *}$ \\
\hline INFRA & $0.289^{* *}$ & 1 & $0.228^{* *}$ & $0.211^{* *}$ & 0.047 & $0.335^{* *}$ & 0.107 & $-0.152^{*}$ & $0.200^{* *}$ \\
\hline ADPE & $0.343^{* *}$ & $0.228^{* *}$ & 1 & $0.343^{* *}$ & $0.192^{*}$ & $0.462^{* *}$ & $-0.278^{* *}$ & -0.103 & 0.081 \\
\hline $\mathbf{E X P}$ & $0.416^{* *}$ & $0.211^{* *}$ & $0.343^{* *}$ & 1 & -0.119 & $0.512^{* *}$ & $-0.380^{* *}$ & 0.077 & $0.228^{* *}$ \\
\hline COM & -0.123 & 0.047 & $0.192^{*}$ & -0.119 & 1 & -0.089 & -0.073 & 0.093 & 0.124 \\
\hline SIZE & $0.327^{* *}$ & $0.335^{* *}$ & $0.462^{* *}$ & $0.512^{* *}$ & -0.089 & 1 & $-0.315^{* *}$ & -0.035 & $0.411^{* *}$ \\
\hline MIM & 0.020 & 0.107 & $-0.278^{* *}$ & $-0.380^{* *}$ & -0.073 & $\begin{array}{c}- \\
0.315^{* *}\end{array}$ & 1 & $-0.497^{* *}$ & -0.097 \\
\hline COER & 0.014 & $-0.152^{*}$ & -0.103 & 0.077 & 0.093 & -0.035 & $-0.497^{* *}$ & 1 & $0.252^{* *}$ \\
\hline NOR & $0.226^{* *}$ & $0.200^{* *}$ & 0.081 & $0.228 * *$ & 0.124 & $0.411^{* *}$ & -0.097 & $0.252^{* *}$ & 1 \\
\hline
\end{tabular}

\subsection{Discussion of results}

Table 5. Results of logistic regression

\begin{tabular}{ccc}
\hline Variables & Coeff. $(\boldsymbol{\beta})$ & P value \\
\hline INFRA & 0.314 & 0.196 \\
ADPE & 0.897 & $0.001^{* * *}$ \\
EXP & 0.916 & $0.00^{* * *}$ \\
COM & -0.474 & $0.047^{* *}$ \\
SIZE & 0.045 & 0.914 \\
MIM & 0.603 & $0.012^{* *}$
\end{tabular}




COER
NOR
-2log likelihood
R-deux of Cox \& Snell
R-deux of Nagelkerke
* ** and *** indicate that the coefficient is significant, respectively, at the thresholds of
$10 \%, 5 \%$ and $1 \%$. Note: Dependent variable: BI_XBRL:1 if the respondent intends to adopt
XBRL, 0 otherwise. Independent variables: INFRA: the total value of infrastructure items
divided by the total number of infrastructure items. ADPE: the total value perceived
advantage items divided by total number of perceived advantage items. EXP: the total value
of the items in the expertise divided by the total number of items in the expertise.COM: the
total value of the items in the communication divided by the total number of items in the
communication. SIZE the total value of size items divided by the total number of size
items. MIM: the total value of the mimetic items divided by the total number of mimetic
items. COER: the total value of the items in the coercive divided by the total number of
items in the coercive. NOR: the total value of normative pressure items divided by the total
number of normative items.

As our study is exploratory, it seeks to examine the factors that may influence the adoption of XBRL focusing on the role of technical, organizational and environmental factors in the Tunisian context.

Our empirical results for the technical factors indicate that the influence comes from the perceived advantages and expertise. Since the variable namely "ADPE" is significant at the rate of $1 \%(\beta=0.897, \mathrm{Sig}=0.001<1)$, because the perception of the relative advantage, which is able to attract the intention to use XBRL (Ilias et al., 2015). Future adopters, consider the increased reliability, the efficient financial reporting process, the transparence of information, the fact of making information more comparable, and other benefits are sources for promoting XBRL in their firms. The expertise variable has a positive and significant coefficient at a rate of $1 \%$. According to this result, a firm has a well-qualified staff with skills and knowledge increases the chance that XBRL will be adopted. Consequently, an expertise allows a margin of safety for the firm to better manage XBRL, while the staff is already familiar with this type of innovation, which is consistent with the results of previous studies (Lakovic et al., 2019; Antônio et al., 2016; Muchliset al., 2019). Although the infrastructure variable still attracts the attention of many researchers and academics in different fields, this factor as a technical variable does not seem to influence the behavioral intent of XBRL adoption. The INFRA variable is insignificant. Thus, there is not a strong relationship between infrastructure and the intention to adopt XBRL, because XBRL is more like a "software" technique that does not require a lot of updating on the existing infrastructure. However, some techniques, e.g. cloud computing or big data 
techniques (Ayoub et al., 2020), require a hardware update in which there may be a significant relationship between infrastructure factor and adoption intent on these recent techniques.

Regarding organizational factors, as expected, the research presents a significant factor $(\mathrm{Sig}=0.047<5)$ to influence the adoption of XBRL. That confirms previous studies which support the important role for communication channels on technology adoption (Rogers, 1983; Jere \& Ngidi, 2020; Angeles, 2014). But we must pay particular attention to this factor because it can have a negative influence on the intention of the adoption in some cases. For example, when the information communicated on XBRL has a pejorative meaning such as: implementation costs, complexity and the question of compatibility or when we use communicating technical words outside the standard lexical field (taxonomy, XML, XLINK, etc.) which are not approved in the accounting community. Consistently with $\mathrm{Yu}$ and Liao (2017), low information literacy for a technology, negatively affects the adoption of information and communication technologies. Concerning the size explanatory factor, we found that the SIZE variable is not significant. So, there is no relationship between the intention to adopt XBRL and size. It seems that this finding is specific to the Tunisian context. In fact, the study by Benabderrahmen et al. (2016), on textile companies in Tunisia, confirms that the size of the company has no impact on ICT adoption. This can be explained by the homogeneity of company sizes, given that the accounting sector is generally made up of small and medium-sized accounting firms.

For the last level of factors, table 5 shows that the intention to adopt XBRL is dependent on the imitation pressure and the normative pressure, similar to the result of Zhang (2017). Mimetic or imitation pressure are significant $(\beta=0.603$, Sig $=0.012<5$ ). Such imitation behavior in accounting firms can be explained by the gains in competitiveness, which helps retain customers by offering the same service provided by other competitors (Lutfi, 2020). However, the normative pressure is significant $(\beta=0.458, \mathrm{Sig}=0.085<10)$ in our research. This reflects the agreement between previous studies (ELansary et al., 2020; Di \& Xia, 2017; Pinsker \& Felden, 2016; Rostami \& Nayeri, 2015). So, the normative pressure comes from professional standards issued by associations and government departments that may prescribe companies to accept XBRL technology as these generally provide a supporting framework and provide credible and understandable information on new technologies. Nevertheless, coercive pressure has a nonsignificant coefficient and therefore there is no relationship with the intention to adopt XBRL. this is consistent with the findings of Hendreson et al. (2012) and Elansary et al. (2020) where they explain that XBRL does not reach a critical mass to have the coercive power to push organizations to change their intention towards the adoption of this technology. 


\section{Additional test}

We propose a second logistic regression in which the size variable is measured quantitatively by the number of employees within the accounting firms.

Table 6. Robustness test

\begin{tabular}{|c|c|c|}
\hline Variables & Coeff. ( $(\beta)$ & $P$ value \\
\hline INFRA & 0.323 & 0.176 \\
\hline ADPE & 0.903 & $0.000 * * *$ \\
\hline EXP & 0.920 & $0.000 * * *$ \\
\hline $\mathrm{COM}$ & -0.480 & $0.043^{* *}$ \\
\hline SIZE & 0.001 & 0.953 \\
\hline MIM & 0.595 & $0.012 * *$ \\
\hline COER & 0.222 & 0.468 \\
\hline NOR & $0 . .470$ & $0.057 *$ \\
\hline -2log likelihood & \multicolumn{2}{|c|}{$168.136 * * *$} \\
\hline R-deux of Cox \& Snell & \multicolumn{2}{|c|}{0.309} \\
\hline R-deux of Nagelkerke & \multicolumn{2}{|c|}{0.417} \\
\hline \multicolumn{3}{|c|}{$\begin{array}{l}*, * * \text { and } * * * \text { indicate that the coefficient is significant, respectively, at the thresholds of } \\
10 \%, 5 \% \text { and } 1 \% \text {. Note: Dependent variable: BI_XBRL: } 1 \text { if the respondent intends to adopt } \\
\text { XBRL, } 0 \text { otherwise. Independent variables: INFRA: the total value of infrastructure items } \\
\text { divided by the total number of infrastructure items. ADPE: the total value perceived } \\
\text { advantage items divided by total number of perceived advantage items. EXP: the total value } \\
\text { of the items in the expertise divided by the total number of items in the expertise.COM: the } \\
\text { total value of the items in the communication divided by the total number of items in the } \\
\text { communication. SIZE the total value of size items divided by the total number of size } \\
\text { items. MIM: the total value of the mimetic items divided by the total number of mimetic } \\
\text { items. COER: the total value of the items in the coercive divided by the total number of } \\
\text { items in the coercive. NOR: the total value of normative pressure items divided by the total } \\
\text { number of normative items. }\end{array}$} \\
\hline
\end{tabular}

The results presented in Table 6 are consistent with the results of the main test, although we have taken another measure of the size variable. The intention to adopt XBRL is strongly related to relative benefits $(\beta=0.903$, Sig $=0.000<1)$, personal expertise $(\beta=0.920, \mathrm{Sig}=0.000<1)$, mimetic pressures $(\beta=0.595$, Sig $=0.012<5)$ and normative pressures $(\beta=0.470, \quad \mathrm{Sig}=0.057<10)$. On the contrary, communication can negatively affect the intention of XBRL adoption. 
Table 7. Summary of findings

\begin{tabular}{c|cccc}
\hline \multirow{2}{*}{ Variables } & \multicolumn{3}{|c}{ Principal Test } & \multicolumn{2}{c}{ Robustness test } \\
\cline { 2 - 5 } & Sign & Sig & Sign & Sig \\
\hline INFRA & + & NS & + & NS \\
ADPE & + & S & + & S \\
EXP & + & S & + & S \\
COM & - & S & - & S \\
SIZE & + & NS & + & S \\
MIM & + & S & + & NS \\
COER & + & NS & + & S \\
NOR & - & S & - & \\
\hline
\end{tabular}

Finally, our results may be summarized as follows:

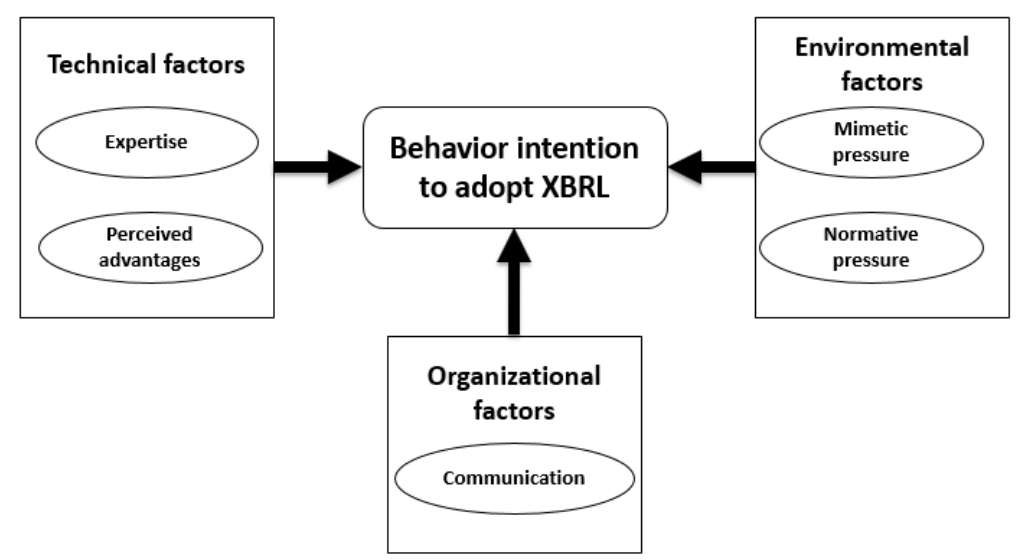

Figure 2. Final conceptual research framework (result of the exploration)

\section{Conclusion}

As an exploratory study to assess the influence of technical, organizational and environmental factors for the adoption of XBRL in the Tunisian context, in which the TOE framework was rethought to add institutional theory and technology acceptance theory, we conducted an empirical study with 172 individuals to test the significance of the factors.

We found that the implementation of XBRL has a positive perception towards the respondents in the Tunisian context, since XBRL brings many advantages for the profession of auditors. Also, we have noted that all three categories of factors can influence XBRL adoption. So Perceived advantages and expertise are technical factors that can influence adoption's intent. moreover, communication, as an organizational factor, plays an important role. However, environmental forces can drive XBRL adoption's intent through normative and mimetic pressures. In 
contrast, the infrastructure, the size of accounting firms and the enforcement pressure are factors that have no relationship with the intention of adopting XBRL.

For theoretical implications, this study is complementary to the existing literature as we draw attention to an undiscovered and undefined context among technology adoption researchers. Also, this survey joins three established theories in the technology adoption literature: TOE framework, institutional theory, and TAM in order to provide a new theoretical model to measure the influence of factors. Finally, we approached a behavioral accounting's search. We hope that our study encourages researchers to multiply investigations in this context and in this field.

Regarding the practical implications, managers and decision-makers are advised to consider the importance of organizational, technological, environmental and individual factors in developing their roadmaps for XBRL adoption. Our results indicate that they should ensure that the company has the technological skills to facilitate the adoption of XBRL. So, managers need to ensure that the company takes communication as an important dimension that must imperatively address the perceived fallout or benefits of this XBRL technology. In addition, the environmental dimension exposes another unique aspect encouraging innovation for companies. In fact, the sharing of information standards by responsible professional bodies and the imitation of other structurally similar companies, including competitors, lead to a greater influence of environmental factors. While at the same time, organizations should react with its pressures to change remains.

Although the conclusions and implications are specific to the Tunisian context, the results of this study can also be used in other countries with similar characteristics. However, there are several limits for this study such as the fac of not taking in consideration the control variables. Despite the conclusion brought by Table 3 , the respondent's demographic information can be interesting especially that the youngest age group is more in line with the intention of adopting XBRL. Also, another limitation that offers further possibilities for future research, is the fact that it only includes accounting views and does not take into account the opinions of other stakeholders such as: managers, banks, public institutions. It would be interesting in the future to work on a larger sample that would include these actors. Future research could cover other factors such as cultural, economic and social factors, as well as factors related to non-adoption. Furthermore, we can conduct a comparative study of countries adopting or not this technology.

\section{References}

Abdolmohammadi, M. J., DeSimone, S. M., Hsieh, T. S. \& Wang, Z. (2017) "Factors associated with internal audit function involvement with XBRL 
implementation in public companies: An international study", International Journal of Accounting Information Systems, vol. 25: 45-56

Abed, S. R. (2018) "The perception of XBRL technology in the Jordanian context: An exploratory study", Research Journal of Applied Sciences, vol. 13, no. 1: $1-4$

Abed, S. S. (2020) "Social commerce adoption using TOE framework: An empirical investigation of Saudi Arabian SMEs", International Journal of Information Management, vol. 53 : 102-118

AlBar, A. M. \& Hoque, M. R. (2019) " Factors affecting cloud ERP adoption in Saudi Arabia: An empirical study", Information Development, vol. 35, no. 1: 150-164

Al-rawahna, A. S. M., Chen, S. C. \& Hung, C. W. (2019) "The barriers of e-government success: An empirical study from Jordan", International Journal of Managing Public Sector Information and Communication Technologies, available on-line at https://ssrn.com/abstract=3498847

Amade, N., Oliveira, T. \& Painho, M. (2020) "Understanding the determinants of GIT post-adoption: perspectives from Mozambican institutions", Heliyon, vol. 6, no. 5

Angeles, R. (2014) "Using the technology-organization-environment framework for analyzing Nike's Considered Index green initiative, a decision support system-driven system", Journal of Management and Sustainability, vol. 4, no. 1: 96

Attewell, P. (1992) "Technology diffusion and organizational learning: the case of business computing", Organization science, vol. 3, no. 1: 1-19

Awa, H. O., Ukoha, O. \& Emecheta, B. C. (2016) "Using TOE theoretical framework to study the adoption of ERP solution", Cogent Business \& Management, vol. 3, no. 1

Awa, H. O., Ojiabo, U. \& Orokor, L. E. (2017) "Integrated technologyorganization-environment (T-O-E) taxonomies for technology adoption", Journal of Enterprise Information Management, vol. 30, no. 6: 893-921

Ayoub, A., Potdar, V., Rudra, A. \& Luong, H. (2019) "Human Factors Affecting XBRL Adoption Success in Lebanese Small to Medium-Sized Enterprises", In International Conference on Big Data and Security, Springer, Singapore, pp. $98-115$

Azam, S., \& Taylor, D. (2011) "Standard Business Reporting in Australia: voluntary take-up issues facing users, preparers and regulators of company financial and business reports", Accountancy Business and the Public Interest, vol. 10, no. 1: 16-41

Bartolacci, F., Caputo, A., Fradeani, A., \& Soverchia, M. (2020) "Twenty years of XBRL: What we know and where we are going", Meditari Accountancy Research, in press

Batcha, H. M., Jan, N. A., Subramani, A. K., \& Julie, R. L. (2017) "Exploring the impact of organization culture on employees' work performance using 
structual equation modeling (SEM) approac", International Journal of Applied Business and Economic Research, vol. 15, no. 16: 483-493

Benabderrahmen, I., Brahmi, M. B. \& Hmida, M. (2016) "Explanatory Factors Determining of ICT Adoption Level in Tunisian Textile Companies", Journal of Behavioural Economics Finance Entrepreneurship Accounting and Transport, vol. 4, no. 1: 1-7

Boulianne, S. \& Theocharis, Y. (2020) "Young people, digital media, and engagement: A meta-analysis of research", Social Science Computer Review, vol. 38 , no. 2 : 111-127

Callaghan, J. \& Nehmer, R. (2009) "Financial and governance characteristics of voluntary XBRL adopters in the United States", International Journal of Disclosure and Governance, vol. 6, no. 4: 321-335.

Chiu, C. N. \& Yang, C. L. (2018) "Competitive advantage and simultaneous mutual influences between information technology adoption and service innovation: moderating effects of environmental factors", Structural Change and Economic Dynamics, vol. 49: 192-205

Choshin, M. \& Ghaffari, A. (2017) "An investigation of the impact of effective factors on the success of e-commerce in small- and medium-sized companies", Computers in Human Behavior, vol. 66: 67-74

Cordery, C. J., Fowler, C. J. \& Mustafa, K. (2011) "A solution looking for a problem: factors associated with the non-adoption of XBRL", Pacific Accounting Review, vol. 23, no. 1: 69-88

Davis, F. D. (1989) "Perceived usefulness, perceived ease of use, and user acceptance of information technology", MIS Quarterly, 319-340.

Debreceny, R., Felden, C. \& Piechocki, M. (2007) "New dimensions of business reporting and XBRL", Deutscher Universitäts-Verlag, GWV Fachverlage $\mathrm{GmbH}$, Wiesbaden, Allemande

Depietro, R., Wiarda, E. \& Fleischer, M. (1990) "The context for change: Organization, technology and environment", The processes of technological innovation, pp. 151-17

Di, W. \& Xia, J. (2017) "Study on the Key Factors for Enterprises Adopting XBRL Technology Based on TOE Framework", 2nd International Conference on Contemporary Education, Social Sciences and Humanities, Atlantis Press

Dias, G. P. (2020) "Determinants of e-government implementation at the local level: an empirical model", Online Information Review, in press

DiMaggio, P. \& Powell, W. (1983) "The Iron Cage revisited: institutional isomorphism and collective rationality in organizational fields", American Sociological Review, vol. 48, no. 2 :147-60

Doolin, B. \& Troshani, I. (2004) "XBRL: a research note", Qualitative Research in Accounting \& Management, vol. 1, no. $2: 93-104$

Doolin, B. \& Troshani, I. (2007) "Organizational adoption of XBRL", Electronic Markets, vol.17, no. 3: 199-209

Ansary, M. E., Oubrich, M., Orlando, B. \& Fiano, F. (2020) "The determinants of XBRL adoption: a meta-analysis", International Journal of Managerial and Financial Accounting, vol.12, no.1: 1-24. 
Felden, C. (2011) "Characteristics of XBRL adoption in Germany", Journal Management Control, vol. 22, no.2:161-186

Giotopoulos, I., Kontolaimou, A., Korra, E. \& Tsakanikas, A. (2017) "What drives ICT adoption by SMEs? Evidence from a large-scale survey in Greece", Journal of Business Research, vol. 81: 60-69

Hanna, H., Haroun, M. H. \& Gohar, N. (2020)"Developing a framework for block chain adoption using TOE model", Journal of Business and Retail Management Research, vol. 15, no.1

Henderson, D., Sheetz, S. D. \& Trinkle, B. S. (2012) "The determinants of interorganizational and internal in-house adoption of XBRL: A structural equation model", International Journal of Accounting Information Systems, vol.13, no. $2: 109-140$

Hoitash, R., Hoitash, U. \& Morris, L. (2021) " eXtensible Business Reporting Language: A Review and Implications for Future Research", Auditing: A Journal of Practice \& Theory, in press

Ilias, A., Ghani, E. K., Baidi, N. \& Abdul, R. (2020) " XBRL adoption: An examination on the Malaysian business reporting system (mbrs) ", Humanities, vol. 8, no. 2: 202-214

Ilias, A., Ghani, E. K. \& Azhar, Z. (2017) " XBRL adoption in Malaysia: Perception of the accountants and auditors", In International Conference on Accounting Studies, Putrajaya, Malaysia, pp. 18-20

Ilias, A., Razak, M. Z. \& Rahman, A. R. (2015) "How potential adopters in Malaysia perceive the relative advantage of eXtensible business reporting language (XBRL)", In International Conference on Accounting Studies, Johor, Malaysia, pp. 338-346

Indrit, T. \& Rao, S. (2007) " Drivers and inhibitors to XBRL adoption: A qualitative approach to build a theory in under-researched areas", International Journal of E-Business Research, vol. 3, no. 4: 98-111

Jere, J. N. \& Ngidi, N. (2020) "A technology, organization and environment framework analysis of information and communication technology adoption by small and medium enterprises in Pietermaritzburg", South African Journal of Information Management, vol. 22, no. 1: 1-9

Lai, P. C. (2017) "The literature review of technology adoption models and theories for the Novelty Technology", Journal of Information Systems and Technology Management, vol. 14, no. 1: 21-38

Lakovic, T., Rondovic, B., Backovic-Vulic, T. \& Ivanovic, I. (2019) "The determinants of XBRL adoption: An empirical study in an emerging economy. In European", Mediterranean, and Middle Eastern Conference on Information Systems, Springer, Cham, pp. 532-546

Lowe, D. J., Bierstaker, J. L., Janvrin, D. J. \& Jenkins, J. G. (2018) "Information technology in an audit context: Have the Big 4 lost their advantage?", Journal of Information Systems, vol. 32, no. 1: 87-107

Lowe, A. \& Locke, J. (2006) " Constructing an efficient frontier of accounting journal quality", The British Accounting Review, vol. 38, no. 3: 321-341 
Lutfi, A. (2020) "Investigating the Moderating Role of Environmental Uncertainty between Institutional Pressures and ERP Adoption in Jordanian SMEs", Journal of Open Innovation: Technology, Market, and Complexity, vol. 6, no. 3: 91

Mandilas, A., Maditinos, D., Pipiliagkopoulos, M. \& Passaportis, A. (2009) "A Cross Country Assessment of the Determinants of the XBRL Adoption", 7th Annual Conference Hellenic Finance and Accounting Association, University of Macedonia, Thessaloniki

Mannan, S., Nordin, S. M., Rafik-Galea, S. \& Rizal, A. R. A. (2017) "The ironies of new innovation and the sunset industry: Diffusion and adoption", Journal of Rural Studies, vol. 55: 316-322

Manohar, P. (2020) " Impact of Adopting Big Data Analytics on Strategic Decisions: A Delphi Study Using the Technology-OrganizationEnvironment (TOE) Framework ", PhD thesis , Capella University

Martins, R., Oliveira, T., Thomas, M. \& Tomás, S. (2019) "Firms continuance intention on SaaS use-an empirical study", Information Technology \& People, vol. 32, no.1 : 189-216

Mathauer, M. \& Hofmann, E. (2019) " Technology adoption by logistics service providers", International Journal of Physical Distribution \& Logistics Management, vol. 49, no. 4: 416-434

Mbaru, E. K. (2018) "Diffusion of a gear-based conservation innovation: adoption patterns and social ecological outcomes", PhD thesis, James Cook University, available on-line at: https://doi.org/10.25903/5d2e828ccca0a

Mousa, R. (2011) "E-government adoption process: XBRL adoption in HM revenue and customs and companies house", $P h D$ thesis, University of Birmingham, available on-line at http://etheses.bham.ac.uk/1752/

Muchlis, F., Primadyan, M., Shauki, E. R. \& Diyanty, V. (2019) "Examining XBRL early adopters: A study of determinants and value relevance", In Asia Pacific Business and Economics Conference, Atlantis Press, pp. 267-274

Nel, G. F. \& Steenkamp, L. P. (2008) "An exploratory study of chartered accountants' awareness and understanding of XBRL", Meditari Accountancy Research, vol.16, no.1: 79-93

Nguyen, T. \& Petersen, T. E. (2017) "Technology adoption in Norway: organizational assimilation of big data", Master's thesis, Norwegian School of Economics, Bergen

Nilakanta, S. \& Scamell, R. W. (1990) "The effect of information sources and communication channels on the diffusion of innovation in a data base development environment", Management Science, vol. 36, no. 1: 24-40

Oliveira, T., Martins, R., Sarker, S., Thomas, M. \& Popovič, A. (2019) "Understanding SaaS adoption: The moderating impact of the environment context", International Journal of Information Management, vol. 49 :1-12 
Piechocki, M., Felden, C., Gräning, A. \& Debreceny, R. (2009) "Design and standardization of XBRL solutions for governance and transparency", International Journal of Disclosure and Governance, vol.6, no. 3: 224-240

Pinsker, R. \& Li, S. (2008) "Costs and benefits of XBRL adoption: Early evidence", Communications of the ACM, vol. 51, no. 3: 47-50

Pinsker, R. E. \& Felden, C. (2016) "Professional role and normative pressure: The case of voluntary XBRL adoption in germany", Journal of Emerging Technologies in Accounting, vol. 13, no. 1: 95-118

Powell, W.W. \& DiMaggio, P.J. (1991) The New Institutionalism in Organizational Analysis, University of Chicago Press: Chicago, USA

Rawashdeh, B. \& Rawashdeh, A (2021) "Factors influencing the usage of XBRL tools", Management Science Letters, vol.11, no.4: 1345-1356

Rogers, E. M. (1983) Diffusion of innovation, NY: Free Press, New York

Rosa, L. F. \& Caserio, C. (2013) "Are auditors interested in XBRL? A qualitative survey of big auditing firms in Italy", In Accounting information systems for decision making, Springer, Berlin, pp. 13-45

Rostami, M. \& Nayeri, M. D. (2015)"Affecting factors on XBRL adoption" Journal of Global Economics, Management and Business Research, vol. 2, no. $4: 171-181$.

Schultz, R. L. \& Slevin, D. P. (1975) "Implementing operations research/management science ", American Elsevier Pub. Co, 153-182

Siangu, G. W., (2015) "The Role of Communication Channels in Disseminating Organizational Innovations: A Case Study of Mumias Sugar CompanyKenya", PhD Thesis, Moi University

Siew, E. G., Rosli, K. \& Yeow, P. H. (2020) "Organizational and environmental influences in the adoption of computer-assisted audit tools and techniques (CAATTs) by audit firms in Malaysia", International Journal of Accounting Information Systems, vol. 36

Steenkamp, L. P. \& Nel, G. F. (2012) "The adoption of XBRL in South Africa: an empirical study", The Electronic Library, vol. 30, no. 3: 409-425

Stenberg, L. \& Nilsson, S. (2020) "Factors influencing readiness of adopting AI: A qualitative study of how the TOE framework applies to AI adoption in governmental authorities", Master's thesis, School of Industrial Engineering and Management, Stockholm

Tornatzky, L. G. \& Klein, K. J. (1982) "Innovation characteristics and innovation adoption-implementation: A meta-analysis of findings", IEEE Transactions on engineering management, vol. 29, no. 1: 28-45

Tornatzky, L. \& Fleischer, M. (1990) The process of technology innovation, Lexington, MA: Lexington Books, 165

Troshani, I. \& Doolin, B. (2007) "Innovation diffusion: a stakeholder and social network view", European Journal of Innovation Management, vol. 10, no. 2: $176-200$ 
Wulandari, S. S. \& Ali, S. (2019) "Incorporating XBRL topics into the accounting curriculum: Empirical evidence from Indonesia", Accounting Education, vol. 28, no. 6: 597-620.

XBRL International. (2019) "An introduction to XBRL", available on-line at: https://www.xbrl.org/.

Yu, T. K., Lin, M. L. \& Liao, Y. K. (2017) "Understanding factors influencing information communication technology adoption behavior: The moderators of information literacy and digital skills", Computers in Human Behavior, vol. 71: 196-208

Zhang, N. (2017) " Research on the factors influencing XBRL financial reporting innovation", 4th International Conference on Education, Management and Computing Technology, Atlantis Press, pp. 1553-1557

Appendix A : Items used for measurement model testing

\begin{tabular}{|c|c|}
\hline \multicolumn{2}{|c|}{ Items name $\quad$ Item text } \\
\hline \multicolumn{2}{|c|}{ Dependent variable } \\
\hline \multicolumn{2}{|c|}{$\begin{array}{l}\text { BI_XBRL Behavior intention to adopt XBRL } \\
\text { Independent variables }\end{array}$} \\
\hline $\begin{array}{l}\text { INFRA1 } \\
\text { INFRA2 }\end{array}$ & $\begin{array}{l}\text { IT infrastructure. } \\
\text { The degree of accessibility on the Internet. }\end{array}$ \\
\hline ADPE1 & Use of XBRL will make financial reporting more transparent. \\
\hline ADPE2 & Use of XBRL will facilitate the analysis of financial information. \\
\hline ADPE3 & The use of XBRL will facilitate the enforcement of regulations. \\
\hline EXP1 & The organization's employees receive adequate training on XBRL. \\
\hline EXP2 & The firm's employees are generally aware of the function of XBRL. \\
\hline COM1 & $\begin{array}{l}\text { The media presence on social networks and other means of communication } \\
\text { allows the promotion of XBRL. }\end{array}$ \\
\hline COM2 & The existence of conferences and events on XBRL. \\
\hline SIZE1 & $\begin{array}{l}\text { The number of employees in the firm influences the decision to implement } \\
\text { XBRL. }\end{array}$ \\
\hline SIZE2 & A significant turnover ensures a type of investment \\
\hline SIZE3 & $\begin{array}{l}\text { Firm accounting that handles a large number of files can use certain } \\
\text { technology }\end{array}$ \\
\hline MIM & $\begin{array}{l}\text { A significant number of accounting firms which are using XBRL affects the } \\
\text { adoption decision }\end{array}$ \\
\hline COER1 & Requirements by banks to submit reports in XBRL format \\
\hline COER2 & Tax authorities' requirements to complete returns in XBRL format \\
\hline NOR1 & XBRL International will influence the decision to use XBRL \\
\hline NOR2 & Order of Chartered Accountants encourages experts to use XBRL \\
\hline
\end{tabular}

